\title{
Comparison of effects of sitagliptin and voglibose on left ventricular diastolic dysfunction in patients with type 2 diabetes: results of the 3D trial
}

Hiroki Oe ${ }^{1 *}$, Kazufumi Nakamura ${ }^{2}$, Hajime Kihara ${ }^{3}$, Kenei Shimada ${ }^{4}$, Shota Fukuda ${ }^{5}$, Tsutomu Takagi ${ }^{6}$, Toru Miyoshi ${ }^{2}$, Kumiko Hirata ${ }^{7}$, Junichi Yoshikawa ${ }^{8}$, Hiroshi Ito ${ }^{2^{*}}$ and FESC, for Effect of a DPP-4 inhibitor on left ventricular diastolic dysfunction in patients with type 2 diabetes and diabetic cardiomyopathy (3D) study investigators.

\begin{abstract}
Background: Left ventricular (LV) diastolic dysfunction is frequently observed in patients with type 2 diabetes. Dipeptidyl peptidase-4 inhibitor (DPP-4i) attenuates postprandial hyperglycemia (PPH) and may have cardio-protective effects. It remains unclear whether DPP-4i improves LV diastolic function in patients with type 2 diabetes, and, if so, it is attributable to the attenuation of PPH or to a direct cardiac effect of DPP-4i. We compared the effects of the DPP-4i, sitagliptin, and the alpha-glucosidase inhibitor, voglibose, on LV diastolic function in patients with type 2 diabetes.

Methods: We conducted a prospective, randomized, open-label, multicenter study of 100 diabetic patients with LV diastolic dysfunction. Patients received sitagliptin $(50 \mathrm{mg} /$ day) or voglibose $(0.6 \mathrm{mg} /$ day). The primary endpoints were changes in the e' velocity and E/e' ratio from baseline to 24 weeks later. The secondary efficacy measures included $\mathrm{HbA1C}, \mathrm{GLP}-1$, lipid profiles, oxidative stress markers and inflammatory markers.

Results: The study was completed with 40 patients in the sitagliptin group and 40 patients in the voglibose group. There were no significant changes in the $e^{\prime}$ velocity and E/e' ratio from baseline to 24 weeks later in both groups. However, analysis of covariance demonstrated that pioglitazone use is an independent factor associated with changes in the $e^{\prime}$ and E/e' ratio. Among patients not using pioglitazone, $e^{\prime}$ increased and the E/e' ratio decreased in both the sitagliptin and voglibose groups. GLP-1 level increased from baseline to 24 weeks later only in the sitagliptin group ( $4.8 \pm 4.7$ vs. $7.3 \pm 5.5 \mathrm{pmol} / \mathrm{L}, p<0.05)$. The reductions in $\mathrm{HbA1C}$ and body weight were significantly greater in the sitagliptin group than in the voglibose group ( $-0.7 \pm 0.6 \%$ vs. $-0.3 \pm 0.4, p<0.005 ;-1.3 \pm 3.2 \mathrm{~kg}$ vs. $0.4 \pm 2.8 \mathrm{~kg}$, $p<0.05$, respectively). There were no changes in lipid profiles and inflammatory markers in both groups.
\end{abstract}

Conclusions: Our trial showed that sitagliptin reduces HbA1c levels more greatly than voglibose does, but that neither was associated with improvement in the echocardiographic parameters of LV diastolic function in patients with diabetes.

Trial registration: Registered at http://www.umin.ac.jp under UMIN000003784

Keywords: Dipeptidyl peptidase 4 (DPP-4) inhibitors, Alpha-glucosidase inhibitor, LV diastolic function

\footnotetext{
* Correspondence: hirokioe@gmail.com; itomd@md.okayama-u.ac.jp

${ }^{1}$ Center of Ultrasonic Diagnostics, Okayama University Hospital, Okayama,

Japan

${ }^{2}$ Department of Cardiovascular Medicine, Okayama University Graduate

School of Medicine, Dentistry and Pharmaceutical Sciences, 2-5-1

Shikata-cho, Okayama 700-8558, Japan

Full list of author information is available at the end of the article
} 


\section{Background}

Diabetes mellitus is a major risk factor for heart failure (HF), especially HF with preserved ejection fraction (HFPEF) development $[1,2]$. Diabetes and HF commonly coexist, and together these conditions are associated with increased morbidity and mortality compared with either condition alone [3-7]. A recent study in Olmsted County, MN, USA, has shown that the prevalence of diabetes in HF patients has increased markedly over time $(3.8 \%$ per year) [8]. An angiotensin-converting enzyme inhibitor (ACEi) or an angiotensin receptor blocker (ARB) is effective in treating $\mathrm{HF}$ as well as reducing insulin resistance in patients with diabetes [9]. Other therapeutic strategies are lacking the same level of effectiveness. Studies have shown that elevated HbA1c is a marker of increased risk of developing HF and, therefore, poor glycemic control may be causally related to the development of $\operatorname{HF}[10,11]$. However, the optimal treatment of hyperglycemia in patients with diabetes to reduce the progression of HF has not been well studied.

Recent studies have shown that dipeptidyl peptidase-4 inhibitor (DPP-4i), which increases the circulating glucagonlike peptide-1 (GLP-1) level, attenuates postprandial hyperglycemia and may have cardio-protective effects [12-14]. In a diabetic rat model, Shigeta et al. [15] demonstrated that DPP4 inhibition reverses left ventricular (LV) diastolic dysfunction via membrane-bound DPP4/stromal cell-derived factor- $1 \alpha$-dependent local actions on angiogenesis and circulating DPP4/GLP-1-mediated inotropic actions. Using HF-model rats, dos Santos et al. [16] reported that sitagliptin $(40 \mathrm{mg} / \mathrm{kg}$ ) administered for 6 weeks exhibited a significant improvement in cardiac contraction and reduction in LV end-diastolic pressure and chamber stiffness. Small pilot studies of GLP-1 have shown potential promise in the treatment of HF patients $[17,18]$. However, it remains unknown whether DPP-4i improves LV diastolic function in patients with type 2 diabetes, and, if so, whether the effect is attributable to the attenuation of postprandial hyperglycemia or to the direct cardiac effect of DPP-4i.

\section{Methods}

We conducted a randomized, prospective, open-label, multicenter study to compare the effects of sitagliptin, a DPP-4 inhibitor, and voglibose, an alpha GI, on LV diastolic function. The assessment was done by Doppler echocardiography in patients with type 2 diabetes at 13 sites between January 2011 and January 2013.

\section{Study population}

Our study population consisted of outpatients with type 2 diabetes from 20 to 85 years of age with LV diastolic dysfunction (LV ejection fraction $>50 \%$, mitral annular early diastolic velocity $\left(\mathrm{e}^{\prime}\right)<8 \mathrm{~cm} / \mathrm{s}$ or the ratio of mitral inflow velocity to e' velocity $\left(E / e^{\prime}\right.$ ratio) $\left.>15\right)$. These patients had not achieved the targets for glycemic control with diet, exercise, sulfonylurea, metformin or pioglitazone treatments. We recruited 100 patients with 50 receiving sitagliptin $(50 \mathrm{mg} /$ day $)$ treatment and 50 voglibose $(0.6 \mathrm{mg} /$ day $)$. The doses of the two drugs used in this study are the recommended therapeutic doses for Japanese patients who are covered by the Japanese National Health Insurance.

The exclusion criteria were: patients being treated with insulin, alpha GI or glinide; and/or exhibited any of the following: type 1 diabetes, HbA1c $\geq 9.0 \%$ (75 mmol/ mol), systolic blood pressure $\geq 160 \mathrm{mmHg}$ and serum creatinine $\geq 1.5 \mathrm{mg} / \mathrm{dL}$ at baseline, myocardial infarction (MI) or stroke within the previous 24 weeks, significant LV hypertrophy at baseline (LV wall thickness $\geq 13 \mathrm{~mm}$ ), atrial fibrillation at baseline, and significant valve diseases (more than or equal to moderately severe valve diseases). The study protocol was approved by the Ethics Committee of Okayama University Graduate School of Medicine, Dentistry, and Pharmaceutical Sciences, and of each hospital. Written informed consent was obtained from all patients before any study procedure.

\section{Study protocol}

The patients were followed for at least 8 weeks to observe that the treatment goal by diet, exercise, sulfonylurea, metformin or pioglitazone was not being achieved. The patients were prospectively and randomly assigned to additional treatment with either sitagliptin $(50 \mathrm{mg} /$ day $)$ or voglibose $(0.6 \mathrm{mg} /$ day) for at least 24 weeks (Fig. 1$)$. We chose a stratified block randomization. Stratified block randomization was computer-generated and done by use of a web-based system (Nouvelle Place Inc. [http:// www.n-place.co.jp/]). Patients were stratified according to age ( $\geq$ or $<65$ years old), HbA1c ( $\geq$ or $<7 \%$ ), e' $(\geq$ or $<$ $6.0 \mathrm{~cm} / \mathrm{s}$ ), and combined use of thiazolidinediones.

Standard echocardiography was performed at the baseline and after 24 weeks of treatment. From the mitral flow velocity pattern, measurements were taken of peak velocities of $\mathrm{E}$ and $\mathrm{A}$ waves, the ratio of their peak velocities (E/A ratio) and deceleration time of the $E$ wave. Spectral pulsed-wave Doppler tissue interrogation of longitudinal mitral annular velocity was recorded throughout the cardiac cycle at the septal annulus in the apical four-chamber view. The peaks of myocardial systolic apically directed velocity (s') and early diastolic velocity (e') were measured.

Additional exploratory analyses including changes in the chamber dimensions and LV ejection fraction were assessed. LV mass was measured by using the American Society of Echocardiography-recommended formula and the end-systolic left atrial volume was measured by using the ellipsoid model [19]. Both values were 
indexed with body surface area in $\mathrm{m}^{2}$. All echocardiographic studies were done when patients were clinically stable on treatment.

\section{Measurements of biochemical parameters}

The following parameters were measured at baseline and after 24 weeks of treatment: complete blood count, liver function test including measurement of AST, ALT and $\mathrm{LDH}$, renal function test including measurement of $\mathrm{BUN}$, creatinine, $\mathrm{Na}, \mathrm{K}$ and $\mathrm{Cl}, \mathrm{HbA1c}$, gastric inhibitory peptide (GIP), GLP-1, C-peptide, CD34, lipid profile including total cholesterol, triglyceride, and high-density lipoprotein (HDL-C), adiponectin, oxidative stress markers including malondialdehyde-modified low density lipoprotein (MDA-LDL) and urine 8-hydroxy-2'-deoxyguanosine (8-OHdG), inflammatory markers including high-sensitive C-reactive protein (hs-CRP) and pentraxin-3 (PTX-3), and estimated glomerular filtration rate (eGFR). HbA1c levels were measured using high-performance liquid chromatography. The number of CD34+ cells was determined by flow cytometry using fluorescein isothiocyanatelabeled CD45 and phycoerythrin (PE)-labeled CD34 antibodies (BD Biosciences, Franklin Lakes, NJ, USA). eGFR $\left(\mathrm{mL} / \mathrm{min} / 1.73 \mathrm{~m}^{2}\right)$ was determined by the modified Modification of Diet and Renal Disease study formula $($ MDRD) for Japanese: eGFR $=194 \times($ age-0.287 $) \times($ serum creatinine-1.094) $\times(0.739$ if female). Brain natriuretic peptide (BNP) concentrations were measured using a commercially available specific radioimmunoassay for human BNP (Shiono RIA BNP assay kit, Shionogi Co., Ltd., Osaka, Japan), respectively. Antihypertensive, antihyperlipidemic and antidiabetic drugs were not changed and anti-oxidant drugs including vitamin $\mathrm{C}$ and $\mathrm{E}$ were not added throughout the study period.

\section{Endpoints}

The primary endpoints were changes in e' and E/e' ratio from baseline to the end of follow-up. The secondary efficacy measures included changes in glucose, HbA1c, GIP, GLP-1, C-peptide, CD34, lipid profile, oxidative stress markers including MDA-LDL and 8-OHdG, inflammatory markers including hs-CRP and PTX-3 and eGFR, and any adverse events.

\section{Statistical analysis}

All of the results are expressed as mean $\pm \mathrm{SD}$ or as proportions (\%). We assumed that $\mathrm{e}^{\prime}$ increased by $1.0 \mathrm{~cm} / \mathrm{s}$ in the sitagliptin group and $0.2 \mathrm{~cm} / \mathrm{s}$ in the voglibose group with a standard deviation of $1.5 \mathrm{~cm} / \mathrm{s}$ [20]. A minimum sample size of 57 participants in each group was required to detect statistical differences in e' with a power of $80 \%$ and $\alpha$ error of $5 \%$. The effects of sitagliptin and voglibose on LV diastolic function were compared using a paired $t$ test. Differences in age, sex, weight, body mass index and blood pressure were compared using the Student's $t$-test. Categorical variables were compared using $X^{2}$ test and Fisher's exact test when appropriate. Differences in secondary efficacy measures between baseline and 24 weeks were compared using a paired $t$-test. A value of $\mathrm{p}<0.05$ was set as the threshold for significance. The effects of sitagliptin and voglibose on LV diastolic function ( $e^{\prime}$ and E/e' ratio) were assessed by analysis of covariance (ANCOVA) after adjustment for covariates that included baseline e' and E/e' ratio, age, sitagliptin/voglibose use and concomitant thiazolidinedione use. Multivariate analysis of

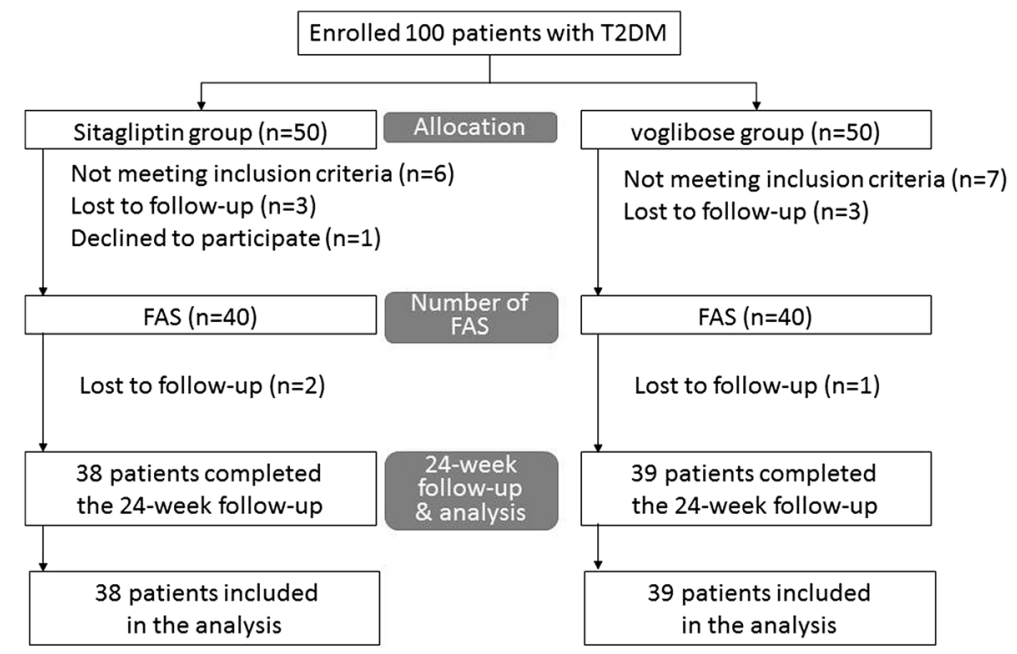

Fig. 1 The study's workflow. Twenty patients were excluded including 6 who were lost to follow-up, 1 who declined to participate and 13 for protocol violation (not meeting inclusion criteria, 12 patients; LVEF < 50\%, 1; under medical treatment with high-dose sulfonylurea). The follow-up study was completed in 77 (77\%) of the patients; 38 received sitagliptin and 39 voglibose 
Table 1 Baseline clinical characteristics

\begin{tabular}{|c|c|c|c|}
\hline Variable & $\begin{array}{l}\text { Sitagliptin } \\
\mathrm{n}=40\end{array}$ & $\begin{array}{l}\text { Voglibose } \\
n=40\end{array}$ & $P$ value \\
\hline Age, y & $67.8 \pm 10.5$ & $66.7 \pm 9.8$ & 0.654 \\
\hline Women, n (\%) & $20(50)$ & $14(35)$ & 0.258 \\
\hline $\begin{array}{l}\text { Diabetes duration, months } \\
\text { (95\% Cl) }\end{array}$ & $48(6-240)$ & $38.5(3-218)$ & 0.145 \\
\hline Body mass index, kg/m2 & $27.7 \pm 4.1$ & $25.7 \pm 4.3$ & 0.038 \\
\hline Abdominal girth, cm & $88.7 \pm 14.3$ & $85.9 \pm 15.6$ & 0.469 \\
\hline Current smoking & $6(15)$ & $4(10)$ & 0.762 \\
\hline Regular alcohol drinkers & $13(33)$ & $17(43)$ & 0.489 \\
\hline \multicolumn{4}{|l|}{ NYHA functional class } \\
\hline Class I, n (\%) & $17(43)$ & $17(43)$ & \multirow[t]{3}{*}{1.000} \\
\hline Class II, n (\%) & $23(58)$ & $22(55)$ & \\
\hline Class III, n (\%) & $0(0)$ & $1(3)$ & \\
\hline \multicolumn{4}{|c|}{ Grades of Diastolic Dysfunction } \\
\hline 0 & $1(2.6)$ & $3(7.5)$ & \multirow[t]{3}{*}{0.0987} \\
\hline 1 & $31(79.5)$ & $34(85.0)$ & \\
\hline 2 & $7(17.9)$ & $3(7.5)$ & \\
\hline Diabetes complication+ & $7(18)$ & $3(8)$ & 0.311 \\
\hline Diabetic retinopathy & $4(10)$ & 2(5) & 0.675 \\
\hline Diabetic nephropathy & $3(8)$ & $0(0)$ & 0.241 \\
\hline Diabetic neuropathy & $2(5)$ & $0(0)$ & 0.494 \\
\hline Hypertension & $37(93)$ & $32(80)$ & 0.193 \\
\hline Hyperuricemia & $31(78)$ & $31(78)$ & 1.000 \\
\hline Hyperlipidemia & $5(13)$ & $4(10)$ & 1.000 \\
\hline Renal disturbance & $7(18)$ & $1(3)$ & 0.057 \\
\hline Mean eGFR & $74.8 \pm 21.7$ & $70.5 \pm 15.3$ & 0.304 \\
\hline Cerebrovascular disease & $3(8)$ & $1(3)$ & 0.615 \\
\hline Myocardial infarction & $5(13)$ & 2(5) & 0.432 \\
\hline Peripheral artery disease & $3(8)$ & $1(3)$ & 0.615 \\
\hline \multicolumn{4}{|l|}{ Anti-diabetic drugs } \\
\hline Pioglitazone & $14(35)$ & $18(45)$ & 0.494 \\
\hline Sulfonylurea & $6(15)$ & $3(8)$ & 0.481 \\
\hline Metformin & $7(18)$ & $1(3)$ & 0.057 \\
\hline$a-G l$ & $1(3)$ & $0(0)$ & 1.000 \\
\hline \multicolumn{4}{|l|}{ Antihypertensive drugs } \\
\hline ARB & $28(70)$ & $27(68)$ & 1.000 \\
\hline Calcium channel blocker & $26(65)$ & $22(55)$ & 0.494 \\
\hline Diuretics & 15(38) & $10(25)$ & 0.335 \\
\hline Others & $11(28)$ & $10(25)$ & 1.000 \\
\hline ACE-I & $2(5)$ & $3(8)$ & \\
\hline a-blocker & $4(10)$ & $1(3)$ & \\
\hline$\beta$-blocker & $6(15)$ & $4(10)$ & \\
\hline aß-blocker & $1(3)$ & $1(3)$ & \\
\hline Aldosterone antagonist & $2(5)$ & $1(3)$ & \\
\hline Antihyperlipidemic drugs & & & \\
\hline
\end{tabular}

Table 1 Baseline clinical characteristics (Continued)

\begin{tabular}{llll}
\hline Statins & $24(60)$ & $22(55)$ & 0.821 \\
Fibrate & $2(5)$ & $2(5)$ & 1.000 \\
Ezetimibe & $5(13)$ & $6(15)$ & 1.000 \\
Eicosapentaenoic acid & $5(13)$ & $2(5)$ & 0.432 \\
Antiplatelet agent & $10(25)$ & $12(30)$ & 0.803 \\
Nitrates & $1(3)$ & $1(3)$ & 1.000 \\
Allopurinol & $1(3)$ & $4(10)$ & 0.359 \\
Uricosuric agents & $0(0)$ & $1(3)$ & 1.000 \\
\hline $\begin{array}{l}\text { Values are means } \pm \text { SD, number of patients (\%), or median (95 \% confidencel } \\
\text { Interval). The continuous variables were compared using Student's } t \text {-test, the } \\
\text { categorical variables were compared using Fisher's exact test, grades of } \\
\text { diastolic dysfunction was compared using Cochran-Armitage trend test, and } \\
\text { the duration of diabetes was compared using the Wilcoxon rank sum test }\end{array}$
\end{tabular}

factors related to changes from baseline to 24 weeks in e' and E/e' ratio levels was performed. All analyses were performed using SAS 9.3 (SAS Institute Inc., Cary, NC, USA).

\section{Results}

\section{Baseline characteristics}

One hundred patients (59 men and 41 women, aged $67.1 \pm 9.6$ years) with type 2 diabetes were enrolled in this study. Fifty patients received sitagliptin $(50 \mathrm{mg} /$ day $)$ treatment and 50 patients received voglibose $(0.6 \mathrm{mg} /$ day) treatment. Twenty patients were excluded including 7 who were lost to follow-up and 13 for protocol violation (not meeting inclusion criteria, 6 patients; LV ejection fraction $<50 \%$, 1 ; under medical treatment with high-dose sulfonylurea.). The follow-up study was completed in 80 (80\%) of the patients; 40 received sitagliptin and 40 voglibose (Fig. 1). Baseline clinical characteristics, including age, sex, body mass index and the type of antidiabetic and antihypertensive medication are shown in Table 1. No patients died, developed cardiovascular events or were admitted to the hospital during the study.

Table 2 Changes in $e^{\prime}$ velocity and E/e' ratio in the sitagliptin and voglibose group

\begin{tabular}{llll}
\hline Variable & $\begin{array}{l}\text { Sitagliptin } \\
n=40\end{array}$ & $\begin{array}{l}\text { Voglibose } \\
\mathrm{n}=40\end{array}$ & $\begin{array}{l}\text { Between-group } \\
\text { difference }\end{array}$ \\
\hline $\mathrm{e}^{\prime}$ & & & \\
Baseline at OW & $5.6 \pm 1.3$ & $5.5 \pm 1.1$ & $\mathrm{p}=0.664$ \\
at 24W & $5.8 \pm 1.3$ & $5.8 \pm 1.1$ & $\mathrm{p}=0.997$ \\
$\Delta \mathrm{e}^{\prime}:$ 24W-0W & $0.2 \pm 1.1$ & $0.3 \pm 0.9$ & $\mathrm{p}=0.702$ \\
E/e' & $12.8 \pm 4.3$ & $11.6 \pm 2.1$ & $\mathrm{p}=0.109$ \\
Baseline at OW & $12.4 \pm 3.4$ & $11.1 \pm 2.7$ & $\mathrm{p}=0.060$ \\
at 24W & $-0.3 \pm 2.5$ & $-0.5 \pm 2.3$ & $\mathrm{p}=0.804$ \\
$\Delta$ E/e': $24 W-0 W$ & & \\
\hline Values are means \pm SD & & & \\
$W$ weeks & & &
\end{tabular}



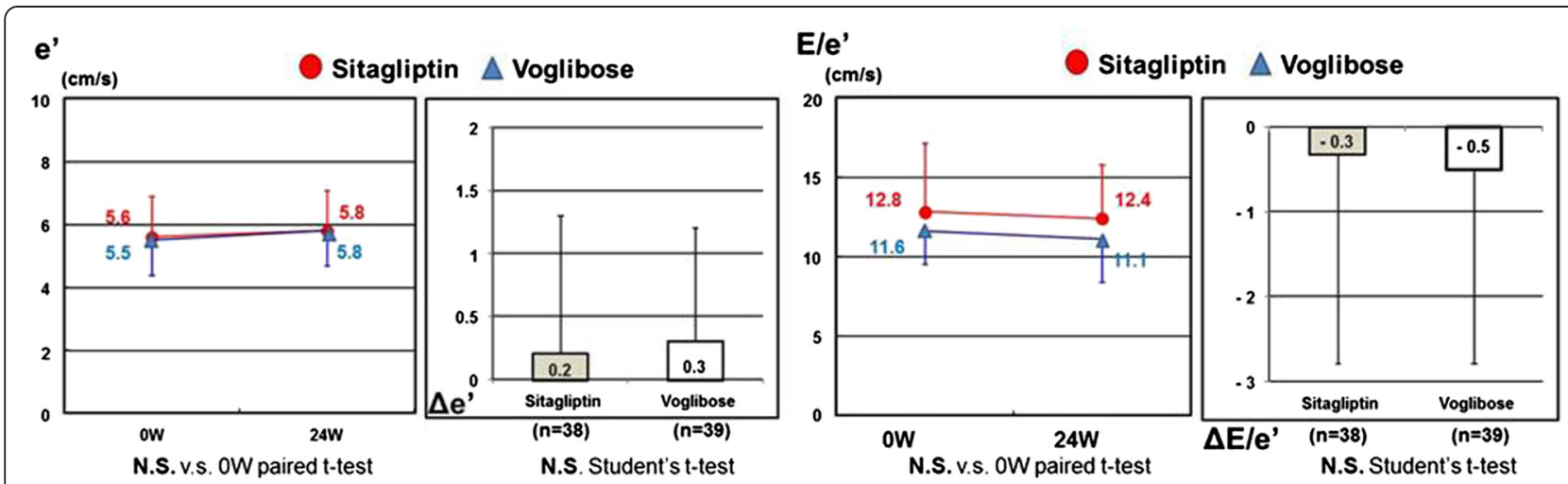

Fig. 2 Changes in $e^{\prime}$ and E/e' between baseline and 24 weeks later. The $e^{\prime}$ velocity and E/e' ratio were comparable between sitagliptin and voglibose groups at baseline. The e' velocity and E/e' ratio showed no changes between baseline and a mean of 24 weeks later in both groups. There was also no significant difference in the magnitude of the changes in e' velocity and E/e' ratio between the two groups. e', mitral annular early diastolic velocity; E/e', ratio of mitral inflow velocity to $e^{\prime}$ velocity; $W$, weeks

\section{The primary endpoint}

The e' velocity and E/e' ratio were comparable between the sitagliptin and voglibose groups at baseline. The e' velocity and $\mathrm{E} / \mathrm{e}^{\prime}$ ratio in both groups showed no changes between baseline and after a mean of 24 weeks (e': sitagliptin $+0.2 \pm 1.1 \mathrm{~cm} / \mathrm{s}$ and voglibose $+0.3 \pm 0.9 \mathrm{~cm} / \mathrm{s} ;$ E/e': sitagliptin $-0.3 \pm 2.5$ and voglibose $-0.5 \pm 2.3$ ). There was also no difference in magnitude of the changes in e' velocity and E/e' ratio between the two groups (Table 2 and Fig. 2).

The effects of sitagliptin and voglibose on LV diastolic function (e' and E/e' ratio) were assessed by ANCOVA after adjustment for covariates that included baseline $e^{\prime}$ and E/e' ratio, age, sitagliptin/voglibose use and concomitant thiazolidinedione use. ANCOVA demonstrated that pioglitazone use is an independent factor associated with changes in e' and E/e' ratio (Table 3). Among patients not using pioglitazone, $\mathrm{e}^{\prime}$ increased and E/e' ratio decreased in both sitagliptin and voglibose groups (e': sitagliptin $+0.5 \pm 1.1 \mathrm{~cm} / \mathrm{s}$ and voglibose $+0.5 \pm 0.9 \mathrm{~cm} /$ s; E/e': sitagliptin $-1.0 \pm 2.7$ and voglibose $-0.8 \pm 2.4$ ).

Multivariate analysis of factors related to changes from baseline to 24 weeks in e' and E/e' ratio levels showed for e', without/with thiazolidinedione was not statistically significant only if adiponectin was added in the model, and for E/e', without/with thiazolidinedione was statistically significant for all models, which implies that without/with thiazolidinedione could be an independent factor associated with changes in the E/e' ratio (Table 4).

\section{Secondary efficacy measures}

The GLP-1 level increased from baseline to 24 weeks later in the sitagliptin group but not in the voglibose group $(4.8 \pm 4.7 \mathrm{pmol} / \mathrm{L}$ vs. $7.3 \pm 5.5 \mathrm{pmol} / \mathrm{L}, \mathrm{p}<0.05$, respectively). The decreases in HbA1c and body weight were significantly greater in the sitagliptin group than in the voglibose group $(-0.7 \pm 0.6 \%$ vs. $-0.3 \pm 0.4 \%, \mathrm{p}<$ 0.005 and $-1.3 \pm 3.2 \mathrm{~kg}$ vs. $0.4 \pm 2.8 \mathrm{~kg}, \mathrm{p}<0.05$, respectively). There were no significant differences in the changes in C-peptide, lipid profile, oxidative stress marker and inflammatory marker between the two groups (Table 5 and Fig. 3). In only the sitagliptin group, and not the voglibose group, did the systolic blood pressure and LV septal wall thickness decrease 24 weeks later $(135 \pm 16 \mathrm{mmHg}$ vs.

Table 3 Factors affecting $e^{\prime}$ and E/e' at week $24^{a}$

\begin{tabular}{|c|c|c|c|c|c|}
\hline Dependent variable & Independent variable & Estimate & $95 \% \mathrm{Cl}$ & & $P$ value \\
\hline \multirow[t]{4}{*}{$e^{\prime}(24 W)$} & $e^{\prime}(0 W)$ & 0.525 & 0.309 & 0.742 & $<0.0001$ \\
\hline & Sitagliptin/Noglibose & -0.047 & -0.455 & 0.362 & 0.821 \\
\hline & Age $-y r$ & -0.028 & -0.054 & -0.003 & 0.032 \\
\hline & without/with TZD & 0.547 & 0.130 & 0.965 & 0.011 \\
\hline \multirow[t]{4}{*}{$E / e^{\prime}(24 W)$} & E/e' (OW) & 0.615 & 0.471 & 0.758 & $<0.0001$ \\
\hline & Sitagliptin/Noglibose & 0.688 & -0.239 & 1.615 & 0.144 \\
\hline & Age $-y r$ & 0.024 & -0.025 & 0.072 & 0.334 \\
\hline & without/with TZD & -1.411 & -2.339 & -0.483 & 0.003 \\
\hline
\end{tabular}

$95 \% \mathrm{Cls}$ and $P$ values were calculated with the use of analysis of covariance (ANCOVA)

${ }^{\mathrm{a}} \mathrm{Cl}$ denotes confidence interval 
Table 4 Multivariate analysis of factors related to changes from baseline to week 24 in $e^{\prime}$ and E/e' ratio levels ${ }^{a}$

\begin{tabular}{|c|c|c|c|c|c|c|}
\hline \multirow[t]{3}{*}{ Model } & \multicolumn{3}{|l|}{$\mathrm{e}^{\prime}[\mathrm{cm} / \mathrm{s}]$} & \multicolumn{3}{|l|}{$E / e^{\prime}$} \\
\hline & Change from baseline & P value ${ }^{b}$ & R2 & Change from baseline & $P$ value ${ }^{b}$ & R2 \\
\hline & Beta $(95 \%$ Cl) & & & Beta $(95 \%$ Cl) & & \\
\hline Model1_Primary model & & & 0.500 & & & 0.609 \\
\hline Baseline & 0.525 (0.309 to 0.742 ) & $<.0001$ & & 0.615 (0.471 to 0.758$)$ & $<.0001$ & \\
\hline Sitagliptin/Noglibose & $-0.047(-0.455$ to 0.362$)$ & 0.8206 & & $0.688(-0.239$ to 1.615$)$ & 0.1436 & \\
\hline Age-yr & $-0.028(-0.054$ to -0.003$)$ & 0.0317 & & $0.024(-0.025$ to 0.072$)$ & 0.3335 & \\
\hline Without/with TZD & 0.547 (0.130 to 0.965$)$ & 0.0109 & & $-1.411(-2.339$ to -0.483$)$ & 0.0034 & \\
\hline $\begin{array}{l}\text { Model2-Add demographic } \\
\text { values }^{b}\end{array}$ & & & 0.522 & & & 0.641 \\
\hline Baseline & 0.520 (0.298 to 0.742 ) & $<.0001$ & & 0.603 (0.456 to 0.750$)$ & $<.0001$ & \\
\hline Sitagliptin/Noglibose & $-0.069(-0.504$ to 0.365$)$ & 0.7509 & & $0.683(-0.271$ to 1.636$)$ & 0.1576 & \\
\hline Age-yr & $-0.025(-0.052$ to 0.002$)$ & 0.0739 & & $0.013(-0.037$ to 0.064$)$ & 0.5964 & \\
\hline Female/Male & $0.243(-0.195$ to 0.681$)$ & 0.2718 & & $-1.114(-2.092$ to -0.137$)$ & 0.0261 & \\
\hline BMI (OW) & $0.033(-0.019$ to 0.084$)$ & 0.2140 & & $-0.037(-0.155$ to 0.081$)$ & 0.5306 & \\
\hline SBP (OW) & $-0.005(-0.020$ to 0.011$)$ & 0.5454 & & $-0.002(-0.036$ to 0.031$)$ & 0.8917 & \\
\hline Pulse (OW) & $-0.003(-0.025$ to 0.019$)$ & 0.7882 & & $0.022(-0.028$ to 0.071$)$ & 0.3911 & \\
\hline Without/with TZD & 0.662 (0.216 to 1.108$)$ & 0.0042 & & $-1.732(-2.711$ to -0.753$)$ & 0.0007 & \\
\hline Model3_Add complications ${ }^{b}$ & & & 0.518 & & & 0.626 \\
\hline Baseline & 0.487 (0.253 to 0.721$)$ & $<.0001$ & & 0.584 (0.425 to 0.744$)$ & $<.0001$ & \\
\hline Sitagliptin/Noglibose & $0.018(-0.426$ to 0.462$)$ & 0.9362 & & $0.642(-0.331$ to 1.615$)$ & 0.1922 & \\
\hline Age-yr & $-0.031(-0.057$ to -0.004$)$ & 0.0228 & & $0.030(-0.020$ to 0.081$)$ & 0.2389 & \\
\hline Diabetes complication & $-0.395(-1.038$ to 0.247$)$ & 0.2238 & & $0.721(-0.799$ to 2.241$)$ & 0.3473 & \\
\hline Hypertension & $0.202(-0.410$ to 0.814$)$ & 0.5131 & & $-0.527(-1.908$ to 0.854$)$ & 0.4491 & \\
\hline Hyperlipidemia & $0.219(-0.317$ to 0.755$)$ & 0.4177 & & $-0.886(-2.086$ to 0.313$)$ & 0.1450 & \\
\hline Renal disturbance & $-0.219(-1.000$ to 0.562$)$ & 0.5780 & & $0.277(-1.453$ to 2.007$)$ & 0.7502 & \\
\hline Without/with TZD & 0.511 (0.068 to 0.954$)$ & 0.0244 & & $-1.302(-2.271$ to -0.334$)$ & 0.0092 & \\
\hline $\begin{array}{l}\text { Model } 4 \text {-Add laboratory } \\
\text { values }^{b}\end{array}$ & & & 0.525 & & & 0.642 \\
\hline Baseline & 0.542 (0.314 to 0.770$)$ & $<.0001$ & & 0.615 (0.469 to 0.761$)$ & $<.0001$ & \\
\hline Sitagliptin/Noglibose & $-0.127(-0.568$ to 0.314$)$ & 0.5671 & & $0.669(-0.314$ to 1.651$)$ & 0.1790 & \\
\hline Age-yr & $-0.023(-0.053$ to 0.006$)$ & 0.1220 & & $0.029(-0.027$ to 0.084$)$ & 0.3045 & \\
\hline WBC (OW) & $-0.000(-0.000$ to 0.000$)$ & 0.7030 & & $0.000(-0.000$ to 0.000$)$ & 0.2013 & \\
\hline AST (OW) & $0.012(-0.008$ to 0.032$)$ & 0.2398 & & $0.003(-0.040$ to 0.046$)$ & 0.8871 & \\
\hline BUN (OW) & $0.009(-0.045$ to 0.063$)$ & 0.7380 & & $-0.019(-0.139$ to 0.101$)$ & 0.7498 & \\
\hline Glucagon (OW) & $-0.001(-0.012$ to 0.010$)$ & 0.8296 & & $-0.010(-0.034$ to 0.014$)$ & 0.3929 & \\
\hline Adiponectin (OW) & $-0.017(-0.049$ to 0.016$)$ & 0.3067 & & $-0.030(-0.102$ to 0.041$)$ & 0.4020 & \\
\hline IVSTh (OW) & $-0.192(-1.847$ to 1.463$)$ & 0.8175 & & $-1.323(-5.000$ to 2.353$)$ & 0.4749 & \\
\hline Without/with TZD & $0.380(-0.181$ to 0.941$)$ & 0.1808 & & $-1.675(-2.916$ to -0.434$)$ & 0.0089 & \\
\hline Model5_Add adiponectin ${ }^{c}$ & & & 0.511 & & & 0.620 \\
\hline Baseline & 0.516 (0.299 to 0.732 ) & $<.0001$ & & 0.623 (0.480 to 0.766$)$ & $<.0001$ & \\
\hline Sitagliptin/Noglibose & $-0.080(-0.490$ to 0.330$)$ & 0.6991 & & $0.587(-0.344$ to 1.519$)$ & 0.2129 & \\
\hline Age-yr & $-0.025(-0.051$ to 0.001$)$ & 0.0637 & & $0.033(-0.016$ to 0.083$)$ & 0.1858 & \\
\hline Adiponectin (OW) & $-0.018(-0.047$ to 0.011$)$ & 0.2169 & & $-0.046(-0.112$ to 0.019$)$ & 0.1610 & \\
\hline Without/with TZD & 0.388 (-0.099 to 0.876$)$ & 0.1169 & & $-1.807(-2.884$ to -0.730$)$ & 0.0013 & \\
\hline
\end{tabular}


Table 4 Multivariate analysis of factors related to changes from baseline to week 24 in $\mathrm{e}^{\prime}$ and E/e' ratio levels ${ }^{\mathrm{a}}$ (Continued)

\begin{tabular}{lllll}
\hline Model6-Remove TZD & & 0.493 & & 0.560 \\
Baseline & $0.480(0.266$ to 0.695$)$ & $<.0001$ & $0.624(0.472$ to 0.777$)$ & $<.0001$ \\
SitagliptinNoglibose & $-0.067(-0.481$ to 0.347$)$ & 0.7471 & $0.566(-0.429$ to 1.561$)$ & 0.2605 \\
Age-yr & $-0.026(-0.052$ to 0.001$)$ & 0.0580 & $0.025(-0.028$ to 0.078$)$ & 0.3505 \\
Adiponectin (OW) & $-0.030(-0.055$ to -0.005$)$ & 0.0187 & $0.010(-0.050$ to 0.070$)$ & 0.7331 \\
\hline
\end{tabular}

${ }^{a}$ The analysis was performed in the full analysis set, with the use of analysis of covariance, WBC denotes white blood cell, AST aspartate transaminase, BUN blood urea nitrogen, IVSTh interventricular septum thickness, and TZD thiazolidinedione

${ }^{b}$ Statistically significant variables (alpha $=0.05$ ) were selected from measured demographics, complications and laboratory variables with the use of two sample t-tests, according to without/with TZD groups in the full analysis set

'For $e^{\prime}$, without/with TZD was not statistically significant (alpha $=0.05$ ) only if adiponectin was added in the model

$128 \pm 10 \mathrm{mmHg}$ and $0.97 \pm 0.15 \mathrm{~mm}$ vs. $0.93 \pm 0.14 \mathrm{~mm}$, respectively) (Table 6).

\section{Adverse events}

Adverse events were observed in 2 patients in the sitagliptin group (hypoglycemia and liver dysfunction) and 4 patients in the voglibose group (diarrhea, edema and gastrointestinal symptoms) (Table 7). Mild hypoglycemia of a patient in the sitagliptin group improved rapidly with dose reduction of sulfonylurea. Hospitalizations because of HF or cardiovascular events were not observed during the study period.

\section{Discussion}

This study is the first randomized trial to compare the impact of glycemic control with sitagliptin and voglibose on LV diastolic function. Our study demonstrated that both sitagliptin and voglibose reduce $\mathrm{HbA1c}$, but the magnitude of reduction of $\mathrm{HbAlc}$ was greater in the sitagliptin group and had a greater increase in the GLP1 level. However, despite the improved glycemic control, the e' velocity and E/e' ratio did not show significant improvement after 24-week treatment with sitagliptin or voglibose. There was also no significant difference in the change in the e' velocity and E/e' ratio between the two groups.

The plasma BNP level, New York Heart Association (NYHA) functional class and the grades of diastolic function (ASE/EAE) did not show significant improvement in either group. Therefore, we conclude that sitagliptin and voglibose had no impact on e' velocity or E/e' ratio in patients with type 2 diabetes and impaired diastolic function.

Elevated HbA1c has been a marker of increased risk of developing HF in patients with diabetes [10, 11]. Poor glycemic control and associated hyperglycemia may be causally related to the development of HF by two mechanisms: (i) through promotion of atherosclerosis and the ensuing coronary artery disease [21] and (ii) by development of a specific diabetic cardiomyopathy by direct damage to the heart muscle $[4,5]$. However, studies examining treatment strategies of intensive glucose control, such as the UKPDS and the more recently completed ACCORD and
ADVANCE studies have not shown statistically significant reductions in HF events in patients assigned to more intensive glucose control strategies when compared with those assigned to standard therapy [22-24]. In our study, the blood glucose level was lowered with sitagliptin and voglibose though the reduction of HbA1c was greater in the sitagliptin group, which also had an associated greater increase in the GLP-1 level. Reduction of body weight and systolic blood pressure was also found in the sitagliptin group. These apparently beneficial changes were not, however, associated with an increase in e' velocity or with a reduction in $\mathrm{E} / \mathrm{e}^{\prime}$ ratio in either groups.

Recently, the SAVOR-TIMI 53 trial showed that DPP4i may increase the risk of HF [25], which is of concern. In this trial, more patients in the saxagliptin group than in the placebo group were hospitalized for HF (3.5\% vs. $2.8 \%$, according to the 2-year Kaplan-Meier estimates; hazard ratio $1.27,95 \% \mathrm{CI}=1.07-1.51 ; \mathrm{p}=0.007)$. However, our results indicate that the BNP value, e' velocity and E/e' ratio do not change during sitagliptin use and, thus, sitagliptin may not be associated with an increased risk of HF or other serious adverse events. Therefore, we can conclude that both sitagliptin and voglibose can be safely used for patients with type 2 diabetes without an increased risk of worsening LV diastolic function.

Although thiazolidinediones activate the peroxisome proliferator-activated receptor $\gamma$ (PPAR $\gamma$ ) system and improve insulin sensitivity to reduce cardiovascular events [26], they are reported to be associated with an increased risk of HF by augmentation of fluid retention [27]. Interestingly, our data demonstrated that pioglitazone is an independent factor that affects the temporal changes in the e' velocity and E/e' ratio. The e' velocity significantly increased in both sitagliptin and voglibose groups if the patients who received pioglitazone were excluded. By contrast, the patients who used pioglitazone showed decreased e' velocity and increased E/e' ratio at the followup assessment. These data indicate that sitagliptin and voglibose might improve LV diastolic function by themselves, and that pioglitazone may attenuate the beneficial impact of these drugs on LV diastolic function. However, it is uncertain whether pioglitazone may worsen HF, 
Table 5 Changes in secondary efficacy measures in the sitagliptin and voglibose group

\begin{tabular}{|c|c|c|c|c|c|}
\hline \multirow[t]{2}{*}{ Variable } & \multicolumn{2}{|l|}{ Sitagliptin } & \multicolumn{2}{|l|}{ Voglibose } & \multirow{2}{*}{$\begin{array}{l}\text { Between-group difference } \\
P \text { value }\end{array}$} \\
\hline & Mean \pm SD & $P$ value & $\overline{M e a n} \pm$ SD & $P$ value & \\
\hline \multicolumn{6}{|l|}{ Glucose } \\
\hline Baseline at OW & $145 \pm 58$ & & $133 \pm 42$ & & 0.304 \\
\hline At $24 \mathrm{~W}$ & $127 \pm 26$ & & $133 \pm 27$ & & 0.354 \\
\hline $24 W-0 W$ & $-23 \pm 60$ & 0.047 & $1 \pm 43$ & 0.916 & 0.083 \\
\hline \multicolumn{6}{|l|}{$\mathrm{HbA1c}$} \\
\hline Baseline at OW & $7.1 \pm 0.7$ & & $6.9 \pm 0.5$ & & 0.273 \\
\hline At $24 \mathrm{~W}$ & $6.4 \pm 0.4$ & & $6.7 \pm 0.5$ & & 0.026 \\
\hline $24 W-0 W$ & $-0.7 \pm 0.6$ & $<0.0001$ & $-0.3 \pm 0.4$ & 0.0004 & 0.002 \\
\hline \multicolumn{6}{|l|}{ GIP } \\
\hline Baseline at OW & $191 \pm 214$ & & $159 \pm 211$ & & 0.517 \\
\hline At $24 \mathrm{~W}$ & $149 \pm 161$ & & $162 \pm 148$ & & 0.759 \\
\hline $24 W-0 W$ & $-21 \pm 226$ & 0.314 & $0.6 \pm 1.6$ & 0.041 & 0.749 \\
\hline \multicolumn{6}{|l|}{ CD34 } \\
\hline Baseline at OW & $1.1 \pm 0.7$ & & $0.9 \pm 0.6$ & & 0.239 \\
\hline At $24 \mathrm{~W}$ & $1.1 \pm 0.5$ & & $0.9 \pm 0.7$ & & 0.160 \\
\hline $24 W-0 W$ & $0.1 \pm 0.5$ & 0.435 & $0.0 \pm 0.5$ & 0.772 & 0.430 \\
\hline \multicolumn{6}{|l|}{ Total cholesterol } \\
\hline Baseline at OW & $184 \pm 27$ & & $185 \pm 33$ & & 0.944 \\
\hline At $24 \mathrm{~W}$ & $178 \pm 29$ & & $183 \pm 37$ & & 0.522 \\
\hline $24 W-0 W$ & $-3 \pm 30$ & 0.603 & $0 \pm 29$ & 0.991 & 0.709 \\
\hline \multicolumn{6}{|l|}{ Triglyceride } \\
\hline Baseline at OW & $155 \pm 107$ & & $141 \pm 74$ & & 0.486 \\
\hline At $24 \mathrm{~W}$ & $132 \pm 62$ & & $127 \pm 72$ & & 0.803 \\
\hline 24W-OW & $-15 \pm 94$ & 0.391 & $-13 \pm 52$ & 0.190 & 0.905 \\
\hline \multicolumn{6}{|l|}{ HDL-C } \\
\hline Baseline at OW & $51 \pm 12$ & & $56 \pm 16$ & & 0.106 \\
\hline At $24 \mathrm{~W}$ & $52 \pm 14$ & & $53 \pm 15$ & & 0.930 \\
\hline 24W-OW & $0.8 \pm 7.9$ & 0.551 & $-3.6 \pm 8.2$ & 0.010 & 0.021 \\
\hline \multicolumn{6}{|l|}{ Adiponectin } \\
\hline Baseline at OW & $11.0 \pm 8.3$ & & $13.3 \pm 8.7$ & & 0.222 \\
\hline At $24 \mathrm{~W}$ & $11.7 \pm 8.8$ & & $12.9 \pm 7.3$ & & 0.528 \\
\hline 24W-OW & $0.5 \pm 1.8$ & 0.092 & $-0.3 \pm 2.9$ & 0.539 & 0.150 \\
\hline \multicolumn{6}{|l|}{ MDA-LDL } \\
\hline Baseline at OW & $106 \pm 34$ & & $110 \pm 37$ & & 0.658 \\
\hline At $24 \mathrm{~W}$ & $113 \pm 34$ & & $109 \pm 36$ & & 0.591 \\
\hline $24 W-0 W$ & $9 \pm 32$ & 0.118 & $1 \pm 38$ & 0.860 & 0.364 \\
\hline \multicolumn{6}{|l|}{ 8-OHdG } \\
\hline Baseline at OW & $11.7 \pm 7.9$ & & $13.5 \pm 10.0$ & & 0.392 \\
\hline At $24 \mathrm{~W}$ & $11.4 \pm 7.4$ & & $14.8 \pm 14.6$ & & 0.221 \\
\hline $24 W-0 W$ & $-0.2 \pm 10.0$ & 0.903 & $1.5 \pm 16.9$ & 0.596 & 0.605 \\
\hline \multicolumn{6}{|l|}{ hs-CRP } \\
\hline Baseline at OW & $3869 \pm 9072$ & & $1358 \pm 2511$ & & 0.099 \\
\hline At $24 \mathrm{~W}$ & $1933+5101$ & & $661+691$ & & 0.147 \\
\hline
\end{tabular}


Table 5 Changes in secondary efficacy measures in the sitagliptin and voglibose group (Continued)

\begin{tabular}{|c|c|c|c|c|c|}
\hline $24 W-0 W$ & $-1929 \pm 6798$ & 0.098 & $-380 \pm 1186$ & 0.059 & 0.186 \\
\hline \multicolumn{6}{|l|}{ PTX-3 } \\
\hline Baseline at OW & $1.8 \pm 1.0$ & & $2.4 \pm 2.7$ & & 0.206 \\
\hline At $24 \mathrm{~W}$ & $1.5 \pm 0.8$ & & $1.6 \pm 0.8$ & & 0.557 \\
\hline $24 W-0 W$ & $-0.3 \pm 0.7$ & 0.006 & $-0.3 \pm 1.2$ & 0.104 & 0.974 \\
\hline \multicolumn{6}{|l|}{ e-GFR } \\
\hline Baseline at OW & $75 \pm 22$ & & $71 \pm 15$ & & 0.304 \\
\hline At $24 \mathrm{~W}$ & $69 \pm 19$ & & $72 \pm 16$ & & 0.411 \\
\hline 24W-OW & $-5 \pm 12$ & 0.014 & $0 \pm 9$ & 0.903 & 0.036 \\
\hline \multicolumn{6}{|l|}{ BNP, pg/ml } \\
\hline Baseline at OW & $39 \pm 48$ & & $34 \pm 35$ & & 0.600 \\
\hline At $24 \mathrm{~W}$ & $40 \pm 41$ & & $28 \pm 24$ & & 0.160 \\
\hline 24W-0W & $1 \pm 40$ & 0.923 & $-5 \pm 22$ & 0.164 & 0.443 \\
\hline
\end{tabular}

GIP gastric inhibitory peptide, GLP-1 glucagon-like peptide-1, CD34 C-peptide, MDA-LDL malondialdehyde-modified low density lipoprotein, 8-OHdG 8-hydroxy-2'-deoxyguanosine, $h s$-CRP high-sensitive C-reactive protein, PTX-3pentraxin-3, eGFR estimated glomerular filtration rate, BNP B-type natriuretic peptide

because no patient who used pioglitazone was hospitalized with HF.

An excessive activity of circulating DPP4 was also found to be independently associated with subclinical LV dysfunction in T2DM patients [28]. Decreased adiponectin levels were associated with LV diastolic dysfunction in patients with known or suspected coronary artery disease [29]. Hibuse et al. reported that serum adiponectin level was elevated after a three-month treatment with sitagliptin [30], and that abenefical effect of sitagliptin on LV

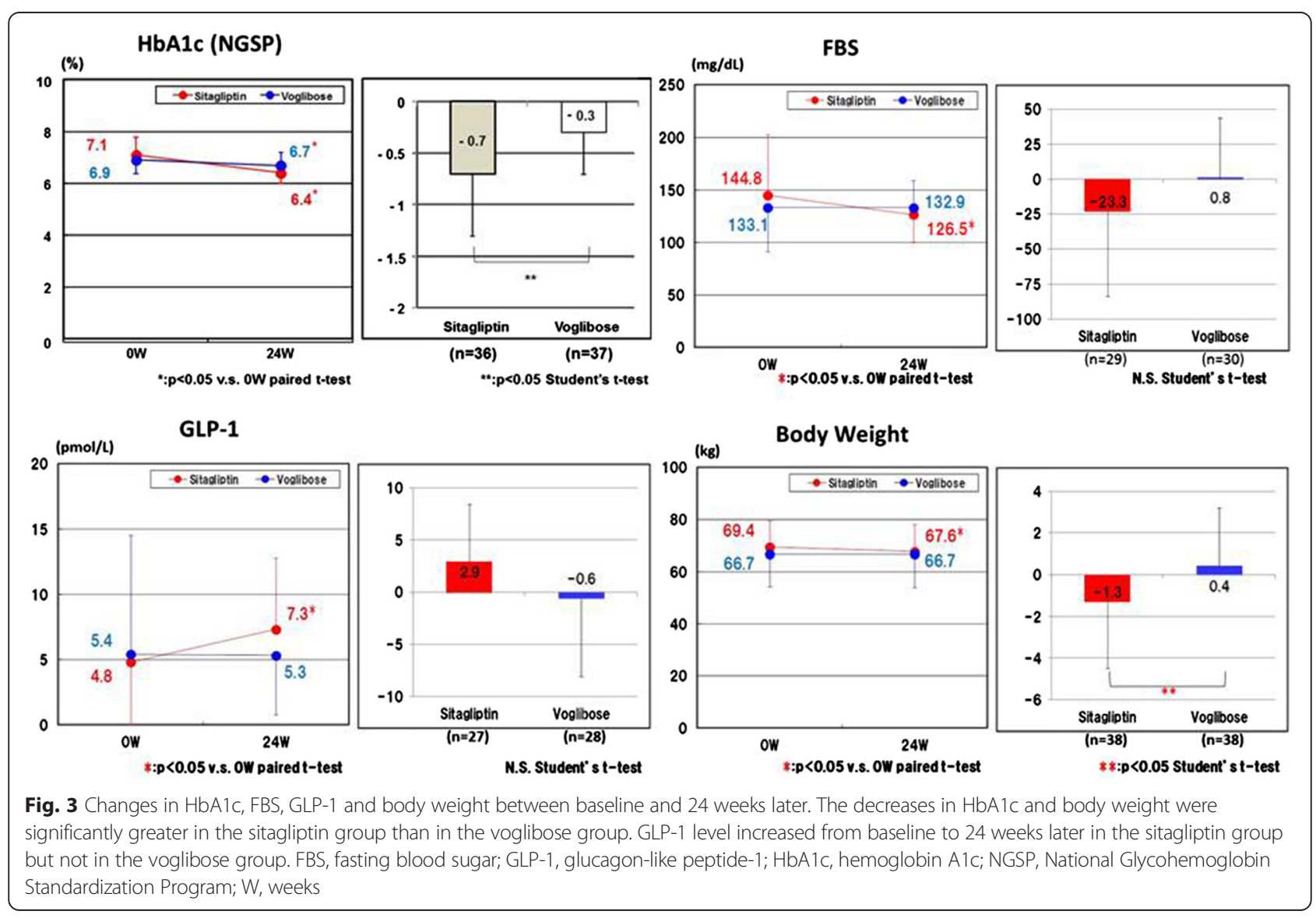


Table 6 Changes in hemodynamic and echocardiographic parameters in the sitagliptin and voglibose group

\begin{tabular}{|c|c|c|c|c|c|}
\hline \multirow[t]{2}{*}{ Variable } & \multicolumn{2}{|l|}{ Sitagliptin } & \multicolumn{2}{|l|}{ Voglibose } & \multirow{2}{*}{$\frac{\text { Between-group difference }}{P \text { value }}$} \\
\hline & Mean \pm SD & $P$ value & Mean \pm SD & $P$ value & \\
\hline \multicolumn{6}{|l|}{$\mathrm{SBP}, \mathrm{mmHg}$} \\
\hline Baseline at OW & $135 \pm 16$ & & $131 \pm 13$ & & 0.180 \\
\hline At $24 \mathrm{~W}$ & $128 \pm 10$ & & $129 \pm 15$ & & 0.855 \\
\hline $24 \mathrm{~W}-0 \mathrm{~W}$ & $-7 \pm 17$ & 0.022 & $-2 \pm 15$ & 0.496 & 0.184 \\
\hline \multicolumn{6}{|l|}{$\mathrm{DBP}, \mathrm{mmHg}$} \\
\hline Baseline at OW & $74 \pm 13$ & & $75 \pm 10$ & & 0.818 \\
\hline At $24 \mathrm{~W}$ & $71 \pm 10$ & & $75 \pm 11$ & & 0.108 \\
\hline 24W-OW & $-2 \pm 14$ & 0.344 & $1 \pm 10$ & 0.779 & 0.349 \\
\hline \multicolumn{6}{|l|}{ Pulse, b.p.m. } \\
\hline Baseline at OW & $71 \pm 11$ & & $71 \pm 10$ & & 0.903 \\
\hline At $24 \mathrm{~W}$ & $69 \pm 12$ & & $71 \pm 11$ & & 0.483 \\
\hline $24 W-0 W$ & $-1 \pm 12$ & 0.653 & $0 \pm 12$ & 0.816 & 0.625 \\
\hline \multicolumn{6}{|l|}{ Body weight } \\
\hline Baseline at OW & $69 \pm 10$ & & $67 \pm 12$ & & 0.294 \\
\hline At $24 \mathrm{~W}$ & $68 \pm 11$ & & $67 \pm 13$ & & 0.736 \\
\hline $24 W-0 W$ & $-1.3 \pm 3.2$ & 0.018 & $0.4 \pm 2.8$ & 0.433 & 0.020 \\
\hline \multicolumn{6}{|l|}{$a^{\prime}, \mathrm{cm} / \mathrm{s}$} \\
\hline Baseline at OW & $8.4 \pm 1.6$ & & $9.0 \pm 1.6$ & & 0.110 \\
\hline At $24 \mathrm{~W}$ & $8.1 \pm 1.8$ & & $9.0 \pm 1.6$ & & 0.031 \\
\hline $24 W-0 W$ & $-0.3 \pm 1.7$ & 0.316 & $0.2 \pm 1.4$ & 0.468 & 0.214 \\
\hline \multicolumn{6}{|l|}{$\mathrm{s}^{\prime}, \mathrm{cm} / \mathrm{s}$} \\
\hline Baseline at OW & $6.6 \pm 1.1$ & & $7.2 \pm 1.2$ & & 0.019 \\
\hline At $24 \mathrm{~W}$ & $6.8 \pm 1.4$ & & $7.0 \pm 1.1$ & & 0.609 \\
\hline $24 W-0 W$ & $0.2 \pm 1.4$ & 0.398 & $-0.2 \pm 1.4$ & 0.412 & 0.237 \\
\hline \multicolumn{6}{|l|}{ Dct } \\
\hline Baseline at OW & $234 \pm 41$ & & $237 \pm 39$ & & 0.769 \\
\hline At $24 \mathrm{~W}$ & $236 \pm 42$ & & $233 \pm 43$ & & 0.765 \\
\hline 24W-OW & $1 \pm 41$ & 0.885 & $-4 \pm 35$ & 0.525 & 0.604 \\
\hline \multicolumn{6}{|l|}{ E velocity, $\mathrm{m} / \mathrm{s}$} \\
\hline Baseline at OW & $68 \pm 16$ & & $62 \pm 11$ & & 0.048 \\
\hline At $24 \mathrm{~W}$ & $69 \pm 14$ & & $63 \pm 14$ & & 0.047 \\
\hline $24 W-0 W$ & $1 \pm 10$ & 0.569 & $0 \pm 12$ & 0.879 & 0.803 \\
\hline \multicolumn{6}{|l|}{ A velocity, $\mathrm{m} / \mathrm{s}$} \\
\hline Baseline at OW & $82 \pm 19$ & & $79 \pm 18$ & & 0.421 \\
\hline At $24 \mathrm{~W}$ & $80 \pm 19$ & & $74 \pm 14$ & & 0.150 \\
\hline $24 W-0 W$ & $-1 \pm 13$ & 0.537 & $-4 \pm 10$ & 0.020 & 0.299 \\
\hline \multicolumn{6}{|l|}{ E/A ratio } \\
\hline Baseline at OW & $0.9 \pm 0.3$ & & $0.8 \pm 0.2$ & & 0.424 \\
\hline At $24 \mathrm{~W}$ & $0.9 \pm 0.2$ & & $0.9 \pm 0.3$ & & 0.668 \\
\hline 24W-OW & $0.0 \pm 0.2$ & 0.402 & $0.0 \pm 0.2$ & 0.157 & 0.651 \\
\hline \multicolumn{6}{|c|}{ Septal thickness, mm } \\
\hline Baseline at OW & $1.0 \pm 0.2$ & & $0.9 \pm 0.1$ & & 0.069 \\
\hline At $24 \mathrm{~W}$ & $0.9 \pm 0.1$ & & $0.9 \pm 0.1$ & & 0.502 \\
\hline
\end{tabular}


Table 6 Changes in hemodynamic and echocardiographic parameters in the sitagliptin and voglibose group (Continued)

\begin{tabular}{|c|c|c|c|c|c|}
\hline 24W-OW & $0.0 \pm 0.1$ & 0.015 & $0.0 \pm 0.1$ & 0.876 & 0.083 \\
\hline \multicolumn{6}{|l|}{ LVEF, \% } \\
\hline Baseline at $\mathrm{OW}$ & $68 \pm 7$ & & $71 \pm 7$ & & 0.209 \\
\hline At $24 \mathrm{~W}$ & $68 \pm 6$ & & $66 \pm 9$ & & 0.179 \\
\hline 24W-OW & $0 \pm 8$ & 0.967 & $-5 \pm 8$ & 0.001 & 0.013 \\
\hline \multicolumn{6}{|l|}{ LVMI, g/m2 } \\
\hline Baseline at OW & $93 \pm 20$ & & $85 \pm 18$ & & 0.085 \\
\hline At $24 \mathrm{~W}$ & $90 \pm 17$ & & $86 \pm 18$ & & 0.239 \\
\hline 24W-OW & $-3 \pm 13$ & 0.195 & $1 \pm 14$ & 0.551 & 0.183 \\
\hline \multicolumn{6}{|c|}{ LA volume index, $\mathrm{ml} / \mathrm{m} 2$} \\
\hline Baseline at $\mathrm{OW}$ & $27.7 \pm 5.9$ & & $26.1 \pm 7.6$ & & 0.346 \\
\hline At $24 \mathrm{~W}$ & $27.7 \pm 7.5$ & & $26.6 \pm 6.3$ & & 0.508 \\
\hline 24W-OW & $0.3 \pm 5.0$ & 0.734 & $0.8 \pm 5.6$ & 0.448 & 0.733 \\
\hline \multicolumn{6}{|c|}{ Urine albumin, mg/g/Cr } \\
\hline Baseline at $\mathrm{OW}$ & $37 \pm 66$ & & $31 \pm 41$ & & 0.603 \\
\hline At $24 \mathrm{~W}$ & $39 \pm 94$ & & $28 \pm 50$ & & 0.533 \\
\hline 24W-OW & $-1 \pm 50$ & 0.889 & $-5 \pm 30$ & 0.339 & 0.723 \\
\hline \multicolumn{6}{|l|}{ BUN } \\
\hline Baseline at OW & $17 \pm 5$ & & $16 \pm 5$ & & 0.760 \\
\hline At $24 \mathrm{~W}$ & $16 \pm 3$ & & $16 \pm 4$ & & 0.824 \\
\hline 24W-OW & $0 \pm 3$ & 0.759 & $0 \pm 4$ & 0.740 & 0.959 \\
\hline
\end{tabular}

diastolic dysfunction is expected. However, there was no significant increase in serum adiponectin level $(0.5 \pm 1.8$, $\mathrm{p}=0.092)$ after 24 weeks of treatment with sitagliptin in this study.

Sitagliptin was associated with an increase in GLP-1, but voglibose was not. Increased GLP-1 may augment diuresis and natriuresis by inhibiting sodium reabsorption from the proximal renal tubule [31]. GLP-1 induces an endothelium-dependent vasorelaxation that is dependent on nitric oxide generation, and this may contribute to reduced peripheral vascular resistance [32]. Clinical and experimental studies have shown that DPP-4i has a moderate blood pressure lowering effect [33]. In this study, sitagliptin significantly lowered SBP, but voglibose did not

Table 7 Adverse events

\begin{tabular}{lll}
\hline Events & Sitagliptin & Voglibose \\
& $\mathrm{n}=40$ & $\mathrm{n}=40$ \\
\hline Hypoglycemia & 2 cases (5.0) & 4 cases (10.0) \\
Diarrhea & $1(2.5)$ & $0(0.0)$ \\
Edema & $0(0.0)$ & $4(10.0)$ \\
Gastrointestinal symptom & $0(0.0)$ & $3(7.5)$ \\
Liver dysfunction & $0(0.0)$ & $2(5.0)$ \\
Total events & $1(2.5)$ & $0(0.0)$ \\
\hline
\end{tabular}

Number of cases (\%) is shown
(135 $\pm 16 \mathrm{mmHg}$ vs. $128 \pm 10 \mathrm{mmHg}$, respectively). There are many studies that demonstrate that reduced systolic blood pressure is associated with regression of LV mass, an increase in e' velocity and a reduction of HF events [34]. Sitagliptin significantly decreased septal wall thickness in our study, but did not decrease LVMI after the 24-week treatment. In the LV hypertrophy rat model induced by isoproterenol infusion, we previously demonstrated that vildagliptin treatment was associated with a reduction in LV mass compared with the control group [35]. However, the duration of exposure to the study drugs may not have been long enough to reverse the effects of years of diastolic dysfunction processes in patients. The present study does not exclude the possibility of either benefit or increased risk with a longer duration of sitagliptin therapy.

\section{Owing to the limited sample size, this study is statistically underpowered}

However, there was almost no difference (much less than $0.8 \mathrm{~cm} / \mathrm{s}$; assumption) of the change in e' in the estimated value between the two groups in this study. So, even if the target number of cases had been achieved, based on current datasets, it would be unlikely that a statistically significant difference would have been obtained.

There are few data about the effect of anti-diabetic drugs on LV diastolic dysfunction. von Bibra et al. 
reported that 16 weeks of treatment with rosiglitazone improved LV diastolic dysfunction evaluated by Doppler echocardiography (e'; $7.9 \mathrm{~cm} / \mathrm{s} \rightarrow 8.9 \mathrm{~cm} / \mathrm{s}, \Delta \mathrm{e}^{\prime}=1.0 \mathrm{~cm} / \mathrm{s}$ ) [20]. However, it remains unknown whether and how anti-diabetic drugs including DPP-4i improve LV diastolic function in patients with type 2 diabetes for now. Further investigation is needed in this area.

We evaluated diastolic function by measuring the e' velocity and the E/e' ratio at the septal side of the mitral annulus. Nagueh et al. reported that it is preferable to use the average e' velocity obtained from the septal and lateral sides of the mitral annulus. We evaluated the changes of e' and the E/e' (24 W-0 W) in this study, and our study population excluded patients with LV ejection fraction $<50 \%$ and myocardial infarction within the previous 24 weeks, thus single-site (septal e') measurements could be applicable.

\section{Limitations}

We acknowledge several limitations in the present study. First, although this study was multicenter and randomized, the drug participation was open-label. Therefore, we used a biomarker, e' velocity, as the primary endpoint. Secondly, we did not measure plasma DPP-4 activity. The study of dos Santos et al. [16] reported that positive correlations were observed between plasma DPP-4 activity and LV end-diastolic pressure and lung congestion in rats.

We did not know whether 50 mg sitagliptin could successfully inhibit plasma DPP-4 activity. We used $50 \mathrm{mg}$ of sitagliptin, which is a standard starting dosage for this medication in Japan, however, outside of Japan, double this dose, i.e. $100 \mathrm{mg}$ of sitagliptin, is generally used. A meta-analysis revealed that, despite the smaller sitagliptin dose of only $50 \mathrm{mg}$, a greater HbA1c reduction $(-0.99 \%$ versus placebo) was observed in Japanese than in nonJapanese patients [36].

Thirdly, because of the small number of patients, we could not assess whether sitagliptin or pioglitazone can attenuate HF events in patients, as this study is statistically underpowered.

Fourth, 6-month treatment might be too short to improve the e' velocity or E/e' ratio. Fifth, echocardiographic studies were performed at each institution by experienced physicians or sonographers and the results were sent to the study center for analysis. These processes are close to those pertaining to real, clinical situations, and diastolic function echocardiographic parameters were supposed to be highly reproducible if performed by experts [37], but inter-institution variability in the examinations may exist and may have influenced the results of this study.

To estimate the inter-institution variability is difficult because the number of cases per institution were too low to evaluate it.
Finally, selection criteria of this study population are strict. It is because we wanted to assess the net effect of DPP inhibitor on LV diastolic function in this study. It is necessary to note whether your patient corresponds to such a patient population or not.

\section{Conclusion}

Our trial showed that sitagliptin reduces HbA1c levels more greatly than voglibose does, but that neither was associated with improvement in the echocardiographic parameters of $\mathrm{LV}$ diastolic function in patients with diabetes.

\section{Abbreviations}

BMI: Body mass index; BNP: Brain natriuretic peptide; DPP-4: Dipeptidyl peptidase IV; eGFR: Estimated glomerular filtration rate; FBS: Fasting blood sugar; GIP: Gastric inhibitory peptide; GLP-1: Glucagon-like peptide-1; Gl: Glucosidase inhibitor; HF: Heart failure; hs-CRP: High-sensitivity C-reactive protein; 8-OHdG: 8-hydroxy-2'-deoxyguanosine; IGT: Impaired glucose tolerance; MDA-LDL: Malondialdehyde-modified low density lipoprotein; NGSP: National glycohemoglobin standardization Program; NYHA: New York heart association; PTX-3: Pentraxin-3; TTE: Trans-thoracic echocardiography; TZD: Thiazolidinedione.

\section{Competing interests}

The authors declare that they have no competing interests.

\section{Authors' contributions}

$\mathrm{HO}, \mathrm{YJ}, \mathrm{HI}$ conceived the study, and participated in its design and coordination and helped to draft the manuscript. HO, KN, HK, KS, SF, TT, TM, KH carried out examinations. All authors read and approved the final manuscript.

\section{Acknowledgements}

This study was supported by the Osaka Foundation for the Prevention of Cancer and Cardiovascular Diseases.

The authors would like to thank Tetsutaro Hamano for assistance with statistical analysis. We also thank the 3D study investigators: Kazufumi Nakamura, MD; Toru Miyoshi, MD, Hiroshi Ito, MD (Okayama University, Okayama, Japan), Hajime Kihara, MD (Kihara Cardiovascular Clinic), Kenei Shimada, MD (Osaka City University of Medicine), Shota Fukuda, MD (Osaka Ekisaikai Hospital), Tsutomu Takagi, MD (Takagi Cardiology Clinic), Kumiko Hirata, MD (Wakayama Medical University) and Junichi Yoshikawa, MD (Nishinomiya Watanabe Cardiovascular Center).

\section{Financial support}

This study was supported by the Osaka Foundation for the Prevention of Cancer and Cardiovascular Diseases.

\section{Author details}

${ }^{1}$ Center of Ultrasonic Diagnostics, Okayama University Hospital, Okayama, Japan. ${ }^{2}$ Department of Cardiovascular Medicine, Okayama University Graduate School of Medicine, Dentistry and Pharmaceutical Sciences, 2-5-1 Shikata-cho, Okayama 700-8558, Japan. ${ }^{3}$ Department of Internal Medicine, Kihara Cardiovascular Clinic, Asahikawa, Japan. ${ }^{4}$ Department of Internal Medicine and Cardiology, Osaka City University of Medicine, Osaka, Japan. ${ }^{5}$ Department of Medicine, Osaka Ekisaikai Hospital, Osaka, Japan. ${ }^{6}$ Takagi Cardiology Clinic, Kyoto, Japan. ${ }^{7}$ Department of Cardiovascular Medicine, Wakayama Medical University, Wakayama, Japan. ${ }^{8}$ Nishinomiya Watanabe Cardiovascular Center, Nishinomiya, Japan.

Received: 20 February 2015 Accepted: 5 June 2015

Published online: 19 June 2015

\section{References}

1. Maisch B, Alter P, Pankuweit S. Diabetic cardiomyopathy. Fact or fiction? Herz. 2011;36:102-15

2. Boyer JK, Thanigaraj S, Schechtman KB, Pérez JE. Prevalence of ventricular diastolic dysfunction in asymptomatic, normotensive patients with diabetes mellitus. Am J Cardiol. 2004;93:870-5. 
3. Kannel WB, Hjortland M, Castelli WP. Role of diabetes in congestive heart failure: the Framingham study. Am J Cardiol. 1974;34:29-34.

4. Rubler S, Dlugash J, Yuceoglu YZ, Kumral T, Branwood AW, Grishman A. New type of cardiomyopathy associated with diabetic glomerulosclerosis. Am J Cardiol. 1972;30:595-602.

5. Boudina S, Abel ED. Diabetic cardiomyopathy revisited. Circulation. 2007;115:3213-23.

6. Aguilar D. Management of type 2 diabetes in patients with heart failure. Curr Treat Options Cardiovasc Med. 2008;10:465-75.

7. Nichols GA, Gullion CM, Koro CE, Ephross SA, Brown JB. The incidence of congestive heart failure in type 2 diabetes - An update. Diabetes Care. 2004:27:1879-84.

8. From AM, Leibson CL, Bursi F, Redfield MM, Weston SA, Jacobsen SJ, et al. Diabetes in heart failure: prevalence and impact on outcome in the population. Am J Med. 2006;119:591-9.

9. Shekelle PG, Rich MW, Morton SC, Atkinson CS, Tu W, Maglione M, et al. Efficacy of angiotensin-converting enzyme inhibitors and beta-blockers in the management of left ventricular systolic dysfunction according to race, gender, and diabetic status: a meta-analysis of major clinical trials. J Am Coll Cardiol. 2003;41:1529-38

10. Lind M, Bounias I, Olsson M, Gudbjörnsdottir S, Svensson AM, Rosengren A Glycaemic control and incidence of heart failure in 20985 patients with type 1 diabetes: an observational study. Lancet. 2011;378:140-6.

11. Iribarren C, Karter AJ, Go AS, Ferrara A, Liu JY, Sidney S, et al. Glycemic control and heart failure among adult patients with diabetes. Circulation. 2001;103:2668-73.

12. Scheen AJ. A review of gliptins in 2011. Expert Opin Pharmacother. 2012;13:81-99.

13. Ussher JR, Drucker DJ. Cardiovascular biology of the incretin system. Endocr Rev. 2012;33:187-215.

14. Drucker DJ, Nauck MA. The incretin system: glucagon-like peptide-1 receptor agonists and dipeptidyl peptidase-4 inhibitors in type 2 diabetes. Lancet. 2006;368:1696-705.

15. Shigeta T, Aoyama M, Bando YK, Monji A, Mitsui T, Takatsu M, et al. Dipeptidyl peptidase-4 modulates left ventricular dysfunction in chronic heart failure via angiogenesis-dependent and -independent actions. Circulation. 2012;126:1838-51.

16. dos Santos L, Salles TA, Arruda-Junior DF, Campos LC, Pereira AC, Barreto $\mathrm{AL}$, et al. Circulating dipeptidyl peptidase IV activity correlates with cardiac dysfunction in human and experimental heart failure. Circ Heart Fail. 2013;6:1029-38.

17. Nikolaidis LA, Mankad S, Sokos GG, Miske G, Shah A, Elahi D, et al. Effects of glucagon-like peptide-1 in patients with acute myocardial infarction and left ventricular dysfunction after successful reperfusion. Circulation. 2004:109:962-5.

18. Sokos GG, Bolukoglu H, German J, Hentosz T, Magovern Jr GJ, Maher TD, et al. Effect of glucagon-like peptide-1 (GLP-1) on glycemic control and left ventricular function in patients undergoing coronary artery bypass grafting Am J Cardiol. 2007;100:824-9.

19. Lang RM, Bierig M, Devereux RB, Flachskampf FA, Foster E, Pellikka PA, et al. Recommendations for chamber quantification: a report from the American Society of Echocardiography's Guidelines and Standards Committee and the Chamber Quantification Writing Group, developed in conjunction with the European Association of Echocardiography, a branch of the European Society of Cardiology. J Am Soc Echocardiogr. 2005;18:1440-63.

20. Von Bibra H, Diamant M, Scheffer PG, Siegmund T, Schumm-Draeger PM Rosiglitazone, but not glimepiride, improves myocardial diastolic function in association with reduction in oxidative stress in type 2 diabetic patients without overt heart disease. Diab Vasc Dis Res. 2008:5:310-8.

21. Bornfeldt KE, Tabas I. Insulin resistance, hyperglycemia, and atherosclerosis. Cell Metab. 2011;14:575-85.

22. UK Prospective Diabetes Study (UKPDS) Group. Intensive blood-glucose contro with sulphonylureas or insulin compared with conventional treatment and risk of complications in patients with type 2 diabetes (UKPDS 33). Lancet. 1998:352:837-53

23. Gerstein HC, Miller ME, Byington RP, Goff Jr DC, Bigger JT, The Action to Control Cardiovascular Risk in Diabetes Study Group, et al. Effects of intensive glucose lowering in type 2 diabetes. N Engl J Med. 2008;358:2545-59.
24. Patel A, MacMahon S, Chalmers J, Neal B, Billot L, ADVANCE Collaborative Group, et al. Intensive blood glucose control and vascular outcomes in patients with type 2 diabetes. N Engl J Med. 2008;358:2560-72.

25. Scirica BM, Bhatt DL, Braunwald E, Steg PG, Davidson J, Hirshberg B, et al. Saxagliptin and cardiovascular outcomes in patients with type 2 diabetes mellitus. N Engl J Med. 2013;369:1317-26.

26. Duan SZ, Usher MG, Mortensen RM. Peroxisome proliferator-activated receptor- $\gamma$-mediated effects in the vasculature. Circ Res. 2008;102:283-94.

27. Nesto RW, Bell D, Bonow RO, Fonseca V, Grundy SM, Horton ES, et al. American heart association; thiazolidinedione Use, fluid retention, and congestive heart failure. A consensus statement from the American Heart Association and American Diabetes Association. Circulation. 2003;108:2941-8.

28. Ravassa S, Barba J, Coma-Canella I, Huerta A, López B, González A, et al. The activity of circulating dipeptidyl peptidase- 4 is associated with subclinical left ventricular dysfunction in patients with type 2 diabetes mellitus. Cardiovasc Diabetol. 2013;12:143

29. Fukuta H, Ohte N, Wakami K, Goto T, Tani T, Kimura G. Relation of plasma levels of adiponectin to left ventricular diastolic dysfunction in patients undergoing cardiac catheterization for coronary artery disease. Am J Cardiol. 2011;108:1081-5.

30. Hibuse T, Maeda N, Kishida K, Kimura T, Minami T, Takeshita E, et al. A pilot three-month sitagliptin treatment increases serum adiponectin level in Japanese patients with type 2 diabetes mellitus-a randomized controlled trial START-J study. Cardiovasc Diabetol. 2014;13:96.

31. Crajoinas RO, Oricchio FT, Pessoa TD, Pacheco BP, Lessa LM, Malnic G, et al. Mechanisms mediating the diuretic and natriuretic actions of the incretin hormone glucagon-like peptide-1. Am J Physiol Renal Physiol. 2011:301:F355-63.

32. Matsubara J, Sugiyama S, Sugamura K, Nakamura T, Fujiwara Y, Akiyama E, et al. A dipeptidyl peptidase-4 inhibitor, des-fluoro-sitagliptin, improves endothelia function and reduces atherosclerotic lesion formation in apolipoprotein $\mathrm{E}$ deficient mice. J Am Coll Cardiol. 2012;59:265-76.

33. Brown NJ. Cardiovascular effects of antidiabetic agents: focus on blood pressure effects of incretin-based therapies. J Am Soc Hypertens. 2012;6:163-8.

34. Solomon SD, Janardhanan R, Verma A, Bourgoun M, Daley WL, Purkayastha $D$, et al. Valsartan In Diastolic Dysfunction (VALIDD) investigators. Effect of angiotensin receptor blockade and antihypertensive drugs on diastolic function in patients with hypertension and diastolic dysfunction: a randomized trial. Lancet. 2007;369:2079-87.

35. Miyoshi T, Nakamura K, Yoshida M, Miura D, Oe H, Akagi S, et al. Effect of vildagliptin, a dipeptidyl peptidase 4 inhibitor, on cardiac hypertrophy induced by chronic beta-adrenergic stimulation in rats. Cardiovasc Diabetol. 2014;13:43.

36. Williams-Herman D, Engel SS, Round E, Johnson J, Golm GT, Guo H, et al. Safety and tolerability of sitagliptin in clinical studies: a pooled analysis of data from 10,246 patients with type 2 diabetes. BMC Endocr Disord. 2010;10:7.

37. Frikha Z, Girerd N, Huttin O, Courand PY, Bozec E, Olivier A, et al. Reproducibility in Echocardiographic Assessment of Diastolic Function in a Population Based Study (The STANISLAS Cohort Study). PLoS One. 2015;10:e0122336

\section{Submit your next manuscript to BioMed Central and take full advantage of:}

- Convenient online submission

- Thorough peer review

- No space constraints or color figure charges

- Immediate publication on acceptance

- Inclusion in PubMed, CAS, Scopus and Google Scholar

- Research which is freely available for redistribution 